\title{
Asbestos Exposure and Histological Sub-Type of Malignant Mesothelioma
}

Franklin $\mathrm{P}^{1^{*}}$, Alfonso $\mathrm{H}^{2^{*}}$, Reid $\mathrm{A}^{2}$, Olsen $\mathrm{N}^{1}$, Shilkin $\mathrm{KB}^{4}$, Brims $\mathrm{F}^{1,3}$, de Klerk $\mathrm{N}^{1,5}$, Musk $\mathrm{AW}^{1,3}$

* Joint first authorship

1 School of Population Health, University of Western Australia, Nedlands, Western Australia.

2 School of Public Health, Curtin University, Bentley, Western Australia

3 Department of Respiratory Medicine, Sir Charles Gairdner Hospital, Nedlands, Western Australia.

4 PathWest, Queen Elizabeth II Medical Centre and University of Western Australia, Nedlands, Western Australia.

5 Telethon Kids Institute, University of Western Australia, Perth, Western Australia

6 Faculty of Medicine, Dentistry and Health Sciences, University of Western Australia, Australia

Address for Correspondence:

Dr Peter Franklin

School of Population Health,

The University of Western Australia

35 Stirling Highway, Crawley, WA 6102,

Email: peter.franklin@health.wa.gov.au

Keywords; Asbestos; mesothelioma; exposure

Word count: 2403 


\section{ABSTRACT:}

Background: Malignant mesothelioma (MM) has distinct histological sub-types (epithelioid, sarcomatoid and biphasic) with variable behaviour and prognoses. It is well recognised that survival time varies with the histological sub-type of MM. It is not known, however, if asbestos exposure characteristics (type of asbestos, degree of exposure) are associated with different histological subtypes.

Aim: To determine if the pathological MM sub-type is associated with the type of asbestos or the attributes of asbestos exposure.

Methods: Cases of MM for the period 1962 until 2012, their main histological sub-type and their most significant source of asbestos exposure were collected from the Western Australian Mesothelioma Registry. Exposure characteristics included, degree of asbestos exposure (including total days exposed, years since first exposure and, for crocidolite only, calculated cumulative exposure), source of exposure (occupational or environmental), form of asbestos handled (raw or processed), and type of asbestos (crocidolite only or mixed fibres).

Results: Patients with the biphasic sub-type were more likely to have occupational exposure (OR 1.83, 1.12 - 2.85) and exposure to raw fibres (OR 1.58, 1.19 - 2.10). However, differences between subtypes in the proportions with these different exposure characteristics were small and unlikely to be biologically relevant. Other indicators of asbestos exposure were not associated with the histological sub-type of mesothelioma.

Conclusions: There was no strong evidence of a consistent role of asbestos exposure indicators in determining the histological sub-type of MM. 


\section{What this paper adds}

- Malignant mesothelioma (MM) has distinct main histological sub-types (epithelioid, sarcomatoid and biphasic)

- It is not known if the type or degree of asbestos exposure can influence the development of different disease sub-types

- Exposure variables that were measured in this study were not consistently associated with MM histological sub-types

- There is little evidence that MM sub-types are associated with different types of asbestos exposure 


\section{INTRODUCTION:}

Malignant Mesothelioma (MM) is an invariably fatal disease, with a median survival time of nine to 12 months from diagnosis. ${ }^{1}$ Three main histological sub-types of MM have been described: epithelioid, sarcomatoid, and biphasic (mixed). ${ }^{2}$ Survival time and response to treatment are known to differ by the histological sub-type with better responsiveness to chemotherapy and a longer survival time of patients with the epithelioid sub-type. ${ }^{134}$

Although the association of $\mathrm{MM}$ with asbestos exposure is well established, ${ }^{5}$ reasons for the development of different subtypes are not well understood. ${ }^{7}$ Very few published studies have investigated the relationship between characteristics of exposure and the development of different histological sub-types. Klebe et al. ${ }^{8}$ reported that compared with non-sarcomatoid cases, patients with sarcomatoid mesotheliomas had significantly more amosite fibres in their lungs. Exposure characteristics of the cases, however, were not reported. ${ }^{8}$ In a study of $238 \mathrm{MM}$ cases, Haber et al. ${ }^{9}$ did not find any associations between either intensity or frequency of exposure and histological subtype but asbestos fibre type was not reported.

The Western Australian Mesothelioma Register has a record of every MM case since the first case was diagnosed in 1960. For most cases occupational and environmental exposure histories are available. $^{10} 11$ The aim of this study, therefore, was to examine the relationship between various characteristics of asbestos exposure and histological sub-type of MM.

\section{METHODS:}

\section{Case ascertainment}

All cases of MM in Western Australia (WA) have been recorded on the Western Australian Mesothelioma Register. All cases are reviewed and confirmed by a committee that includes an expert pathologist, a respiratory physician, an epidemiologist and an occupational physician using 
information collected from reports of pathology laboratories, hospitals and clinics. For each case, age, sex, dates and methods of diagnosis, histological sub-type, site of disease, date of death, and available history of asbestos exposure are documented. The study was approved by the Western Australian Department of Health Human Research Ethics Committee (HREC).

\section{Pathological diagnosis}

The reported histological sub-type of mesothelioma was recorded as epithelioid, sarcomatoid, biphasic or undefined. Every report of the pathologist responsible for the cytological or histological diagnosis of each case was reviewed by an expert pathologist (KBS) to confirm the diagnosis. All available cytology, histology, immunohistochemistry and/or electron-microscopy reports were considered for the assessment. Whenever possible, the original slides were retrieved for confirmation of diagnosis where there was doubt as to the diagnosis and also to attempt to classify where the classification was unclear. Some cases were diagnosed by cytology only. These were accepted as true MM cases and recorded as epithelioid on the register. However, it is possible that some of these cases could have been biphasic as only the epithelioid component is manifest in the cytology; no cases can be or were diagnosed as sarcomatoid, or biphasic, on cytology alone. Cases diagnosed by cytology only were considered as a separate group for this study.

\section{Exposure assessment}

For cases diagnosed until the late 1980s, a self-reported questionnaire detailing occupational and non-occupational exposure to asbestos was completed. In more recent cases, exposure information has been collected from clinical notes, doctors' letters and reports, and advocacy groups. Patients were asked about their occupational histories, including descriptions of tasks that had involved exposure to asbestos, as well as residential or other non-occupational exposures. The Mesothelioma Register Committee reviews each case and seeks to classify the primary source of asbestos exposure. 
There is a list of 29 exposure codes that include occupational, residential and environmental exposures as well as ‘no known' and ‘unknown' exposure. 'No known' exposure is coded if the case has been intensively questioned and no identifiable source of exposure to asbestos can be identified. 'Unknown' exposure is coded if the case has not been questioned at all or if some source of asbestos exposure has been noted but sufficient details of the exposure are not. There are 22 codes for occupational exposures and five codes for non-occupational exposure. If there is more than one source of exposure, the Committee considered the most significant exposure for coding. For example, occupational exposure would usually be considered more significant than nonoccupational exposure.

An important source of exposure in Western Australia was the crocidolite mine and mill in the north of the state. This operated between 1943 and 1966. The mining town of Wittenoom was situated about $12 \mathrm{~km}$ from the mine and mill but was highly contaminated with crocidolite fibres from mine tailings that were distributed around the town. For MM cases that had worked and/or lived in Wittenoom the mine/mill or town was considered the primary source of exposure.

The characteristics of asbestos exposure assessed in this study included, where available, duration of exposure (for occupational cases only), time since first exposure, source of asbestos exposure (occupational or non-occupational), form of asbestos handled (raw, processed or unclear), type of asbestos (crocidolite only or mixed fibres) and cumulative exposure (for crocidolite only). For 'form of asbestos' handled, anyone working in mining, transport or asbestos production, as well as residents or visitors to Wittenoom were categorised as exposed to raw asbestos, while cases who had worked with asbestos products or had non-occupational exposures other than from Wittenoom were categorised as exposed to processed asbestos. Type of asbestos was categorised as 'crocidolite only' or 'mixed fibres'. Former workers of the Wittnoom mine and ex-residents of the Wittenoom 
townsite are considered to have had almost exclusive exposure to crocidolite and were categorised as such, while all others were categorised as exposed to 'mixed-fibres'. Finally, the association between histological sub-types and cumulative exposure was only assessed in cases who had worked in the Wittenoom mine or lived in the town of Wittenoom as exposure concentrations have been estimated for these people. ${ }^{1011}$

\section{Lung fibre counts}

Lung asbestos bodies and fibres were collected from a subsample of cases $(n=122)$ either from autopsies or from lung tissue resected at surgical procedures. The lung specimens were processed using Pooley's method for counting fibres of all types using transmission electron microscopy, ${ }^{12}$ and asbestos bodies were isolated and counted using Smith and Naylor's method with light microscopy. ${ }^{13}$ Energy dispersive X-ray spectroscopy (EDAX) analysis was used to identify the type of asbestos fibre through comparison with the International Union against Cancer (UICC) reference profiles. $^{14}$

\section{Data analysis}

Variables with normal distribution were described by their means and standard deviations: nonnormally distributed variables (cumulative exposure and duration of exposure for former Wittenoom workers and residents) were transformed to their natural logarithm and reported as geometric means and 95\% confidence intervals. Proportions were used to summarise categorical variables. Unadjusted group comparisons were performed using one-way ANOVA or chi square statistics. Multinomial logistic regression models were then constructed to investigate the association between exposure variables and histological sub-types, adjusting for sex and age at diagnosis. Histological sub-type was the dependent variable and the epithelioid sub-type was the reference group for each of the models. Linear regression models, adjusting for sex, were used for the quantitative exposure variables, cumulative exposure and duration of exposure, in cases who 
had their primary exposure as a Wittenoom worker and/or resident. For lung fibre counts the data were not normally distributed so were compared between groups using both Chi-square (for proportions) and Kruskal-Wallis (for concentrations) tests. All statistical tests reported are twotailed. The data were managed and analysed with Stata version 12.1 (StataCorp, College Station, TX).

\section{RESULTS}

There were 2,024 (1,744 males) confirmed cases of MM between 1960 and December 2012. These included 713 confirmed epithelioid, 412 biphasic and 260 sarcomatoid sub-types. Four hundred and ninety-nine were diagnosed by cytology only and the pathological sub-type could not be determined in 140 cases. The undetermined cases were not included in the analyses. Of the remaining 1,884 cases, 228 had ‘unknown’ ( $n=164)$ or ‘no-known’ $(n=64)$ exposure and were also excluded from further analyses. The final analyses, therefore, included 1656 cases (Table 1).

Cases with sarcomatoid MM and those diagnosed by cytology only were slightly older at diagnosis than those with epithelioid or biphasic histological sub-types (Table 1). There was a longer latency for the sarcomatoid sub-type. Proportionally, more males had sarcomatoid and biphasic sub-types, while peritoneal MM was significantly less common for the sarcomatoid sub-type (Table 1). 
Table 1: Demographic characteristics by pathological sub-type of MM

\begin{tabular}{|c|c|c|c|c|}
\hline & $\begin{array}{l}\text { Epithelioid } \\
\text { N=614 }\end{array}$ & $\begin{array}{l}\text { Cytology only } \\
\qquad \mathrm{N}=440\end{array}$ & $\begin{array}{c}\text { Biphasic } \\
\mathbf{N}=\mathbf{3 8 0}\end{array}$ & $\begin{array}{c}\text { Sarcomatoid } \\
\qquad \mathbf{N}=222\end{array}$ \\
\hline Age at diagnosis (yrs)* & $66.2(11.3)$ & $68.7(11.9)$ & $66.9(11.3)$ & $70.4(9.4)$ \\
\hline Sex $(\text { Male })^{\dagger}$ & $546(88.9)$ & $379(86.1)$ & 347 (91.3) & $210(94.6)$ \\
\hline Pleural mesothelioma $^{\dagger}$ & $576(93.8)$ & $396(90.0)$ & $361(95.0)$ & $220(99.1)$ \\
\hline Time since $1^{\text {st }}$ exposure $(y r s)^{* \neq}$ & 42.7 (11.7) & $43.5(10.8)$ & 40.9 (11.4) & 44.9 (11.7) \\
\hline
\end{tabular}

\#p-value across groups, calculated by one way ANOVA for age at diagnosis and time since $1^{\text {st }}$ exposure; and chi square test for sex and MM site.

*mean(SD)

${ }^{\dagger} \mathrm{n}(\%)$

${ }^{\ddagger}$ Data available for 1271 cases only (488 epithelioid, 292 biphasic, 155 sarcomatoid and 336 cytology only) 
Patients with the biphasic sub-type were significantly more likely to have had occupational exposure and been exposed to raw asbestos than the epithelioid group (Table 2). Cytology only cases were also more likely than epithelioid patients to have had occupational exposure (Table 2). There were no significant differences between the groups with regards to crocidolite-only exposure resulting from living or working at Wittenoom (Table 2). 
Table 2: Asbestos exposure characteristics and pathological sub-type of MM

\begin{tabular}{|c|c|c|c|c|c|c|c|}
\hline & $\begin{array}{l}\text { Epithelioid } \\
\qquad \mathrm{N}=614\end{array}$ & $\begin{array}{c}\text { Cytology } \\
\text { only } \\
\text { N=440 }\end{array}$ & $\begin{array}{l}\text { Biphasic } \\
\text { N=380 }\end{array}$ & $\begin{array}{l}\text { Sarcomatoid } \\
\qquad N=222\end{array}$ & $\begin{array}{c}\text { OR1* } \\
(95 \% \mathrm{CI})\end{array}$ & $\begin{array}{c}\text { OR2* } \\
(95 \% \mathrm{CI})\end{array}$ & $\begin{array}{c}\text { OR3* } \\
(95 \% \mathrm{CI})\end{array}$ \\
\hline $\begin{array}{l}\text { Crocidolite (Wittenoom) } \\
\text { exposure }^{\dagger}\end{array}$ & $176(28.7)$ & 135 (30.7) & 129 (33.9) & $47(21.2)$ & $\begin{array}{c}1.19 \\
(0.90,1.56)\end{array}$ & $\begin{array}{c}1.28 \\
(0.97,1.70)\end{array}$ & $\begin{array}{c}0.78 \\
(0.54,1.14)\end{array}$ \\
\hline Occupational exposure $^{\dagger}$ & $496(80.8)$ & $357(81.1)$ & $333(87.6)$ & $198(89.2)$ & $\begin{array}{c}1.14 \\
(0.77,1.69)\end{array}$ & $\begin{array}{c}1.83 \\
(1.18,2.85)\end{array}$ & $\begin{array}{c}1.43 \\
(0.83,2.48)\end{array}$ \\
\hline Raw asbestos fibre ${ }^{\dagger \#}$ & 197 (36.9) & $164(43.2)$ & $155(47.8)$ & $58(31.0)$ & $\begin{array}{c}1.38 \\
(1.05,1.82)\end{array}$ & $\begin{array}{c}1.58 \\
(1.19,2.10)\end{array}$ & $\begin{array}{c}0.88 \\
(0.61,1.26)\end{array}$ \\
\hline
\end{tabular}

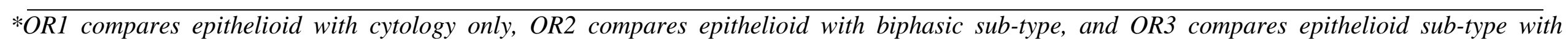
sarcomatoid sub-type. Values have been adjusted for age and sex.

${ }^{\#}$ Numbers are lower due to missing data

${ }^{\dagger} \mathrm{n}(\%)$ 


\section{Subgroup analyses}

More detailed asbestos exposure estimates were available for 341 cases from Wittenoom (Table 3).

There were no differences between the sub-type groups for either cumulative exposure or average daily exposure intensity but cases with biphasic sub-type had a significantly shorter duration of exposure.

There were 122 lung tissue samples. The most common asbestos fibres found in lung tissue were crocidolite (98.3\% of samples). Chrysotile was present in $31.9 \%$ of samples and amosite in $13.1 \%$. Fibre numbers were low for both amosite and chrysotile. Neither fibre numbers nor proportions differed across the histological groups (Table 4). 
Table 3: Crocidolite exposure characteristics of subjects exposed at Wittenoom

$\begin{array}{cccc}\text { Epithelioid } & \text { Cytology only } & \text { Biphasic } & \text { Sarcomatoid } \\ \mathbf{N}=120 & \mathrm{~N}=103 & \mathrm{~N}=91 & \mathrm{~N}=\mathbf{2 7}\end{array}$

\begin{tabular}{|c|c|c|c|c|}
\hline & $\mathrm{N}=120$ & $\mathrm{~N}=103$ & $\mathrm{~N}=91$ & $\mathbf{N}=27$ \\
\hline Days exposed to asbestos ${ }^{\dagger}$ & $559.5(427.5-732.2)$ & $588.2(438.8-788.4)$ & $367.2(269.9-499.7)^{*}$ & $546.2(324.4-918.7)$ \\
\hline Cumulative asbestos (f/mL-yr) $^{\dagger}$ & $9.8(7.1-13.4)$ & $8.7(6.2-12.3)$ & $7.3(5.1-10.6)$ & $7.4(4.0-14.0)$ \\
\hline Ave Daily Intensity $(\mathrm{f} / \mathrm{mL})^{\dagger}$ & $6.4(4.9-8.3)$ & $5.4(4.1-7.2)$ & $7.6(5.6-10.3)$ & $5.2(3.1-8.7)$ \\
\hline
\end{tabular}

*Significantly different to epithelioid sub-type.

${ }^{\dagger}$ Geometric Mean (95\%CI). Adjusted for sex 
Table 4: Asbestos body and fibre counts for subset of MM cases that had undergone lung resection

\begin{tabular}{|c|c|c|c|c|c|c|c|}
\hline & & $\mathbf{A B}^{\mathbf{a}}$ & $\mathbf{A F}^{\mathbf{b}}$ & Amphiboles $^{b}$ & Crocidolite $^{b}$ & Chrysotile $^{b}$ & Amosite $^{b}$ \\
\hline \multirow{3}{*}{$\begin{array}{l}\text { Epithelioid } \\
(n=45)\end{array}$} & Median & 1204.00 & 6.46 & 5.96 & 5.71 & .01 & .01 \\
\hline & Range & $<1.00-388875.00$ & $0.10-4619.00$ & $0.10-4619.00$ & $<0.01-4619.00$ & $<0.017 .72$ & $<0.01-5.40$ \\
\hline & \% Present & 100 & 100 & 100 & 97.8 & 28.9 & 15.6 \\
\hline \multirow{3}{*}{$\begin{array}{l}\text { Biphasic } \\
(n=51)\end{array}$} & Median & 575.00 & 6.87 & 6.43 & 6.43 & .01 & .01 \\
\hline & Range & $10.00-668042.00$ & $0.32-2203.98$ & $<0.01-2159.00$ & $<0.01-2159.00$ & $<0.01-44.98$ & $<0.01-3.52$ \\
\hline & \% Present & 100 & 100 & 98 & 98.0 & 29.4 & 13.7 \\
\hline \multirow{3}{*}{$\begin{array}{l}\text { Sarcomatoid } \\
(n=26)\end{array}$} & Median & 819.00 & 8.79 & 8.43 & 7.89 & .01 & .01 \\
\hline & Range & $40.00-231923.00$ & $0.17-2107.30$ & $0.17-2107.30$ & $0.14-2107.30$ & $<0.01-5.19$ & $<0.01-2.69$ \\
\hline & $\%$ Present & 100 & 100 & 100 & 100 & 42.3 & 7.7 \\
\hline
\end{tabular}

AB: Asbestos bodies

AF: Asbestos fibres

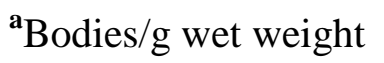

$\mathbf{b}_{\text {Fibres/ug dry weight }}$ 


\section{DISCUSSION}

Reasons for the development of different histological subtypes of $\mathrm{MM}$ are not well understood. ${ }^{7}$ In this study, we investigated if there was an association between exposure characteristics and MM subtypes in a large, well characterised data set of cases. Although there were some statistically significant differences in exposure variables between the groups in this study, they were small and do not provide compelling evidence that different types of exposure can account for different histological subtypes.

The most consistent differences for exposure characteristics were found in cases with biphasic sub-type. Patients with the biphasic sub-type were more likely to have occupational exposure and exposure to raw fibres. They were also more likely to be exposed to crocidolite only but this was not statistically significant. For those exposed to crocidolite only, cases with the biphasic sub-type had a slightly shorter duration of exposure than the other two sub-types but there was no difference in either cumulative- or intensity of exposures between the groups. It is not known if these findings are relevant. Biologically plausible reasons do not exist and they are not supported by the existing, albeit scarce, epidemiological data. ${ }^{8}$

The strength of this study is the complete ascertainment of mesothelioma cases, as the Western Australian Mesothelioma Registry has direct access to every case of MM in the State. However, the pathological diagnosis of MM is challenging. ${ }^{15}{ }^{16}$ According to the latest guidelines ${ }^{16}$ the diagnosis should be based on the results obtained from an adequate biopsy in the context of appropriate clinical, radiological and surgical findings. ${ }^{16}$ In this study, most (75\%) of the cases were diagnosed histologically (which includes histochemistry), considered as an accurate and valid diagnostic system. ${ }^{16}$ Diagnosis and subtype classification was based on a review of existing records and when classification was unclear, a review of the original 
slides (if available). The review was done by a pathologist (KBS) with considerable experience and expertise in MM. However, in individual cases the category may be suspect, particularly for the biphasic subtype. Any misclassification of subtypes would have been nondifferential with regards to exposure variables and therefore more likely to underestimate the observed differences, although probably not to the extent that would affect the overall conclusions. Some cases were recorded as epithelioid based only on cytology and, although it has been shown that the cytological diagnosis can be reliable, ${ }^{17}$ these cases were treated as a separate group in the statistical analysis of this paper due to potential misclassification in the diagnosis.

There were limitations of this study with regards the assessment of asbestos exposure. Firstly, assessment was based on occupational histories, self-reported exposure questionnaires, and clinical notes, which are reviewed by the Mesothelioma Registry Committee. Although a primary route of exposure is assigned to each case, this is unlikely to fully reflect all routes of exposure and exposure types for all cases. Secondly, it is difficult to investigate the effects of different individual fibre types as the mixed fibre exposure group in this study are likely to have had some exposure to crocidolite. Indeed the lung fibre data in this study shows very few (2/122) tissue samples that do not contain crocidolite. The asbestos used in asbestos products, particularly asbestos cement products, in Western Australia was mainly chrysotile and amosite but after 1955 crocidolite was used as well. ${ }^{18}$ Klebe et al. ${ }^{8}$ found that there were higher concentrations of amosite in the lungs of the sarcomatoid cases the reviewed and it remains possible that fibre type may affect the development of a particular MM subtype.

In this study there were some differences in exposure characteristics of patients with different histological sub-types of MM. However, these differences were small and do not provide 
evidence for a consistent role of indicators of asbestos exposure in determining the histological sub-type of MM.

Acknowledgments: We acknowledge Dr Timothy Threlfall for his contribution in accessing the data source and both Dr Vincent Williams and Dr Pierre Filion for their work on the preparation and counting of lung asbestos fibres

Competing interests: None declared

Funding: National Health and Medical Research Council (NHMRC) Project Grant \#634458 


\section{REFERENCES}

1. Musk AW, Olsen N, Alfonso H, et al. Predicting survival in malignant mesothelioma. Eur Respir J 2011;38:1420-4.

2. Hillerdal G. Malignant mesothelioma 1982: Review of 4710 published cases. Brit J Dis Chest 1983;77:321-43.

3. Ceresoli GL, Locati LD, Ferreri AJMa, et al. Therapeutic outcome according to histologic subtype in 121 patients with malignant pleural mesothelioma. Lung Cancer 2001;34:279-87.

4. Chapman A, Mulrennan S, Ladd B, et al. Population based epidemiology and prognosis of mesothelioma in Leeds, UK. Thorax 2008;63:435-39.

5. de Klerk N, Musk AW. Epidemiology of mesothelioma. In: Robinson B, Chahinian AP, eds. Mesothelioma. London: Martin Dunitz Ltd., 2002:339-49.

6. Berry G. Models for mesothelioma incidence following exposure to fibers in terms of timing and duration of exposure and the biopersistence of the fibers. Inhal Toxicol 1999;11:111-30.

7. Craighead JE. Epidemiology of mesothelioma and historical background. Recent Results Cancer Res 2011;189:13-25.

8. Klebe S, Brownlee NA, Mahar A, et al. Sarcomatoid mesothelioma: a clinical-pathologic correlation of 326 cases. Mod Pathol 2010;23:470-9.

9. Haber SE, Haber JM. Malignant mesothelioma: a clinical study of 238 cases. Ind Health 2011;49:166-72.

10. Armstrong BK, de Klerk NH, Musk AW, et al. Mortality in miners and millers of crocidolite in Western Australia. Brit J Ind Med 1988;45:5-13.

11. Hansen J, De Klerk NH, Musk AW, et al. Individual exposure levels in people environmentally exposed to Crocidolite. Appl Occup Environ Hyg 1997;12:485-90. 
12. Pooley FD, Clark NJ. Quantitative assessment of inorganic fibrous particulates in dust samples with an analytic transmission electron microscope. Ann Occup Hyg 1979;22:253-71.

13. Smith MJ, Naylor B. A method for extracting ferruginous bodies from sputum and pulmonary tissue. Am J Clin Pathol 1972;58:250-4.

14. de Klerk NH, Musk AW, Williams V, et al. Comparison of measures of exposure to asbestos in former crocidolite workers from Wittenoom Gorge, Western Australia. Am J Ind Med 1996;30:579-87.

15. Arrossi AV, Lin E, Rice D, et al. Histologic Assessment and Prognostic Factors of Malignant Pleural Mesothelioma Treated With Extrapleural Pneumonectomy. Am J Clin Pathol 2008;130:754-64.

16. Husain AN, Colby T, Ordonez N, et al. Guidelines for Pathologic Diagnosis of Malignant Mesothelioma: 2012 Update of the Consensus Statement from the International Mesothelioma Interest Group. Arch Pathol Lab Med 2012;137:647-67.

17. Segal A, Sterrett GF, Frost FA, et al. A diagnosis of malignant pleural mesothelioma can be made by effusion cytology: results of a 20 year audit. Pathol 2013;45:44-8.

18. Western Australian Committee on Hazardous Substances. Asbestos Cement Products. Western Australia: Health Department of Western Australia, 1990. 